\title{
LETTER TO THE EDITOR (JUL 26, 2017) CONCERNING THE PAPER "IMPACT OF ELECTROMAGNETIC RADIATION EMITTED BY MONITORS ON CHANGES IN THE CELLULAR MEMBRANE STRUCTURE AND PROTECTIVE ANTIOXIDANT EFFECT OF VITAMIN A - IN VITRO STUDY"
}

Dear Editor,

With great enthusiasm I read the paper authored by Lewicka et al. entitled "Impact of electromagnetic radiation emitted by monitors on changes in the cellular membrane structure and protective antioxidant effect of vitamin A - In vitro study" [1]. Authors of this paper had evaluated the effect of electromagnetic radiation ( $1 \mathrm{kHz}$ frequency, $220 \mathrm{~V} / \mathrm{m}$ electric field) emitted by liquid-crystal-display (LCD) monitors on the concentration of malondialdehyde (MDA) as a marker of lipid peroxidation. They had also studied the antioxidant role of vitamin A during the exposure of blood platelets to electromagnetic radiation generated by liquidcrystal-display (LCD) monitors. These authors concluded that electromagnetic radiation possibly had a negative effect on the cellular membrane structure (observed as alterations in MDA concentration) and reported a possible protective role of vitamin A.

Over the past decade, my colleagues and I have studied the health effects of electromagnetic fields. The paper authored by Lewicka et al. has some major shortcomings. The first shortcoming of this paper is due to its problematic radiation source. The authors state "In a laboratory stand designed for reconstruction of the parameters of electromagnetic radiation generated by display screens $(1 \mathrm{kHz}, 220 \mathrm{~V} / \mathrm{m})$, a flat capacitor was the source of electromagnetic field." Although the majority of modern LCD monitors generate weak electric fields in the kilohertz range [2], the strength of the electromagnetic fields produced by each LCD depends on many parameters such as the size of display. By the way, it's not clear that the parameters used in this study $(1 \mathrm{kHz}, 220 \mathrm{~V} / \mathrm{m})$ correspond to which type of LCD monitor.

Another major shortcoming comes from the distance between the samples and the source of electromagnetic radiation. Lewicka et al. [1] state that "Preserving constant conditions of the environment the preparation was exposed to the activity of the electromagnetic field of $1 \mathrm{kHz}$ frequency and $220 \mathrm{~V} / \mathrm{m}$ intensity (corresponding to a distance of $15 \mathrm{~cm}$ from the monitor) for $30 \mathrm{~min}$ and $60 \mathrm{~min}$." According to the Occupational Safety and Health Administration (OSHA), the preferred viewing distance from the eye to the front surface of the computer screen is $50-100 \mathrm{~cm}$ (20-40 inches) [3]. In this light, simulating the electromagnetic radiation at a distance of $15 \mathrm{~cm}$ away 
from a LCD display is irrational and cannot represent a normal viewing distance.

Furthermore, LCD monitors not only generate electromagnetic radiation but also emit high levels of blue light [4] which possibly induces damage associated with oxidative processes [5]. Substantial evidence now shows that the emission of blue light by digital devices may cause some health problems [6]. Therefore, the radiation source used in the study conducted by Lewicka et al. [1] cannot model a real LCD monitor.

Key words:

Electromagnetic fields, EMF, Monitors, Cell membrane, Antioxidants, Vitamin A

\section{REFERENCES}

1. Lewicka M, Henrykowska G, Zawadzka M, Rutkowski M, Pacholski K, Buczyński A. Impact of electromagnetic radiation emitted by monitors on changes in the cellular membrane structure and protective antioxidant effect of vitamin A In vitro study. Int J Occup Med Environ Health. 2017;30(5): 695-703, https://doi.org/10.13075/ijomeh.1896.00851.

2. Sandström M. Electromagnetic fields in offices. Int J Occup Saf Ergon. 2006;12(2):137-47, https://doi.org/10.1080/108035 48.2006.11076677.
3. Occupational Safety and Health Administration [Internet]. Washington: Administration [cited 2017 Jul 25]. Computer Workstations eTool. Available from: https:/www.osha.gov/ SLTC/etools/computerworkstations/components_monitors. html.

4. Oh JH, Yoo H, Park HK, Do YR. Analysis of circadian properties and healthy levels of blue light from smartphones at night. Sci Rep. 2015;5:11325, https://doi.org/10.1038/ srep11325.

5. Dillon J. The photophysics and photobiology of the eye. J Photochem Photobiol B. 1991;10(1-2):23-40.

6. Hatori M, Gronfier C, Van Gelder RN, Bernstein PS, Carreras J, Panda S, et al. Global rise of potential health hazards caused by blue light-induced circadian disruption in modern aging societies. NPJ Aging Mech Dis. 2017;3:9, https://doi. org/10.1038/s41514-017-0010-2.

Seyed Mohammad Javad Mortazavi

Fox Chase Cancer Center, Philadelphia, USA

Department of Diagnostic Imaging

Doss Lab R-432

333 Cottman Avenue, Philadelphia, PA 19111, USA

(e-mail: s.m.javad.mortazavi@fccc.edu)

This work is available in Open Access model and licensed under a Creative Commons Attribution-NonCommercial 3.0 Poland License - http://creativecommons.org/ licenses/by-nc/3.0/pl/deed.en. 